\title{
Estimation of the economic impact of temperature changes induced by a shutdown of the thermohaline circulation: an application of $F U N D$
}

\author{
P. Michael Link • Richard S. J. Tol
}

Received: 5 May 2006 / Accepted: 11 December 2009 / Published online: 16 January 2010

(C) The Author(s) 2009. This article is published with open access at Springerlink.com

\begin{abstract}
The integrated assessment model FUND 2.8n is applied in an assessment to estimate the magnitude of the general market and non-market impacts of temperature changes caused by a possible shutdown of the thermohaline circulation (THC). The monetized impacts of this change in environmental conditions are determined for 207 individual countries for two scenarios: one warming scenario in which the THC weakens but remains intact, and another in which the THC breaks down. Eight different response patterns are identified. The dominant pattern is that a THC shutdown has an offsetting effect on the underlying warming trend. Depending on whether the impacts of warming are initially beneficial or detrimental, the economic
\end{abstract}

P. M. Link ( $ه)$

Research Group Climate Change and Security, KlimaCampus, Hamburg University,

Bundesstrasse 53 \#018, 20146 Hamburg, Germany

e-mail: michael.link@zmaw.de

P. M. Link

Research Unit Sustainability and Global Change, Center for Marine and Atmospheric Sciences,

Hamburg University, Hamburg, Germany

R. S. J. Tol

Economic and Social Research Institute, Dublin, Ireland

R. S. J. Tol

Institute for Environmental Studies, Vrije Universiteit,

Amsterdam, The Netherlands

R. S. J. Tol

Department of Spatial Economics, Vrije Universiteit,

Amsterdam, The Netherlands

R. S. J. Tol

Department of Engineering and Public Policy, Carnegie Mellon University,

Pittsburgh, PA, USA 
effects of a THC shutdown show distinct regional variability. Key economic sectors affected are water resources and energy consumption, as well as cardiovascular and respiratory diseases among health impacts. The maximum national impact of a shutdown of the THC turns out to be of the magnitude of a few per cent of GDP, but the average global impact is much smaller. The results indicate that the temperature effect of a THC shutdown does not create an insurmountable economic threat on a global scale, but may cause severe damages to individual countries. However, a consideration of other climatic impacts such as precipitation and sea level changes is likely to alter the identified trends in economic development.

\section{Introduction}

The potential weakening of the thermohaline circulation (THC) due to climate change has captured the public mind. Often referred to as a collapse of the ocean conveyer belt that brings warmth to Europe, the public picture is one of an impending ice-age. Based on more sophisticated analysis, scientists and policy makers worry about the unprecedented impacts this scenario of climate change would have.

Indeed, the THC can be considered to be one of the tipping elements of the planet's climate system (Lenton et al. 2008). Depending on the extent of additional freshwater input into the North Atlantic, the THC may shift from one stable condition (THC on) to another (THC off). The rate of freshwater input is important in determining the effectiveness of bringing the THC to a halt (Stocker and Schmittner 1997). The higher the additional freshwater input, the more readily any mechanisms stabilizing the THC will be overcome and the circulation breaks down.

Model ensemble simulations of the fate of the THC show that already a small additional freshwater flux into the North Atlantic leads to a weakening but not to a complete shutdown of the THC (Stouffer et al. 2006). The response of the THC to climate change is usually a gradual spin-down (Manabe and Stouffer 1994; Mikolajewicz et al. 2007). Although it has to be noted that there is a large uncertainty connected to this quantity, the critical freshwater input necessary for such a shutdown of the THC is on the order of $0.1 \mathrm{~Sv}$ or higher (Kuhlbrodt et al. 2009). Based on expert opinion, a weakening of the THC as a consequence of global warming is much more likely to occur than a complete shutdown, even though some of the experts that were interviewed about their view of the fate of the THC assess the probability of a complete shutdown in scenarios of a multiplication of the atmospheric $\mathrm{CO}_{2}$ concentration as significantly different from zero (Zickfeld et al. 2007).

A shutdown of the THC would create a substantial cooling over the North Atlantic. In hosing experiments, in which a large pulse of freshwater is added to the northern North Atlantic, the reduction of the mean air temperature can locally exceed $15^{\circ} \mathrm{C}$ (Wood et al. 2003, 2006; Vellinga 2004). In addition, the entire hemisphere is subject to cooling. Model intercomparisons indicate that the pattern of temperature change as a consequence of a THC shutdown is complex, with cooling over the western North Atlantic and some warming further east (Stouffer et al. 2006). However, it has to be noted that if an underlying global warming trend is considered, this trend dominates any effects of a weakened THC. Consequently, a weakening 
of the THC then only has a slightly offsetting effect on the overall warming (Gregory et al. 2005).

In addition to temperature changes, altered rainfall patterns can also be observed (Vellinga and Wood 2002). The Northern Hemisphere is likely to experience reduced rainfall while the shift of the Intertropical Convergence Zone, which follows a THC shutdown, leads to sometimes pronounced precipitation increases over South America and Africa. Concerning the oceans, sea level height is also expected to be affected. In the North Atlantic region, such changes in hydrographic conditions would cause an increase in sea level of approximately $25-50 \mathrm{~cm}$ (Levermann et al. 2005; Vellinga and Wood 2008). This would augment the effects of global warming on global sea level height and predominately occurs in the North Atlantic and the Arctic Seas. Coinciding with the overall rise in sea level is a regional acceleration of this change in hydrography, which can reach up to $25 \mathrm{~mm} / \mathrm{a}$ near the American Atlantic coast in case of a THC shutdown. This effect adds to the environmental stress by changes in temperature and precipitation.

In an assessment of ecosystem responses to a shutdown of the THC, Higgins and Vellinga (2004) show that the implications of such a drastic environmental change is not confined to the region of the North Atlantic, in which the change in THC strength actually takes place. Through particular teleconnections, the ecological impacts are likely to occur globally and are quite heterogeneously distributed geographically. Such ecological impacts are not only driven by changes in temperature but also by changes in precipitation patterns, on which changes in net primary productivity are predominantly dependent.

Among the most pronounced ecological consequences of northern hemisphere cooling following a shutdown of the THC is a southward shift of the forest line and a change of temperate biome distribution (Köhler et al. 2005), which in turn has implications on agricultural production as well. Model results indicate that forests are likely to expand in regions that experience increases in precipitation such as eastern South America while growth of deserts and biome losses will occur in regions like the Sahel that would receive less precipitation (Higgins and Vellinga 2004). While changes of terrestrial carbon storage are expected to be small (Köhler et al. 2005), the overall production of terrestrial vegetation is expected to decline slightly (Vellinga and Wood 2002). The resulting effect on the atmospheric $\mathrm{CO}_{2}$ content is, however, hard to predict, as it is critically dependent on the underlying climatic conditions when the THC shuts down (Köhler et al. 2005).

In an analysis of possible economic implications of a shutdown of the THC, Nævdal and Oppenheimer (2007) define a model that considers several possible thresholds for THC change and assess the optimal regulation of $\mathrm{CO}_{2}$ emissions to possibly prevent a THC shutdown. Results indicate that in order to avoid a "catastrophic" risk of a THC shutdown, specific acceptable values of temperature and temperature increase may not be exceeded. However, in the model simulations only the maximum acceptable rate of temperature increase was surpassed in finite time while the threshold with regard to temperature itself was never reached. Keller and others (2004) assess abatement policies to prevent a collapse of the THC in the context of uncertainty and show that the influence of incomplete knowledge on the optimal $\mathrm{CO}_{2}$ abatement strategy is critically dependent on the importance given to ecological and economic investment irreversibilities. 
The assessment of economic consequences of a THC shutdown in this paper focuses on the impacts of temperature changes. Obviously, there are economic impacts arising from altered precipitation patterns and sea level rise as well. So far, assessments of such effects have always been conducted without considering changes in THC strength.

Changes in precipitation patterns directly influence agricultural production (Fischer et al. 2005). A global assessment indicates that climate change has little impact on agricultural cereal production at a global scale. However, a regional differentiation shows that some regions can be significantly affected, with the most severe changes occurring in tropical semi-arid developing countries.

Sea level changes affect coastal zones in all regions of the world. An analysis with a CGE model of the economy-wide impacts of a sea level rise of $25 \mathrm{~cm}$ until the year 2050 shows that neglecting coastal protection leads to land losses that have detrimental implications for the entire economy (Bosello et al. 2007). Furthermore, public utility is also negatively affected. In contrast, full coastal protection would lead to regional increases in GDP. It has to be noted, though, that the geographic distribution of sea level rise following a THC shutdown differs substantially from a general increase in sea level of $25 \mathrm{~cm}$ worldwide. An application of FUND, which looks at the economic impacts of sea level changes following a catastrophic event like the collapse of the West Antarctic ice sheet, shows that there would be a magnification of the effects of sea level rise on the world's coasts by an order of magnitude due to rapidly rising costs for coastal protection and very high damages stemming from land losses and forced migration (Nicholls et al. 2008; Tol 2009).

Fankhauser and Tol (2005) draw attention to the fact that direct market and nonmarket impacts of climate change are not the only economic consequences of altered environmental conditions. Long-term effects include changes in people's willingness to save, capital accumulation, and technological progress. Climate change impacts on capital and savings are generally negative, thus disregarding these quantities in climate change assessments causes impacts to be underestimated.

In this paper, we estimate the general magnitude of monetized market and nonmarket impacts of temperature changes induced by a shutdown of the THC. This extends the assessments of Link and Tol (2004) and Ceronsky et al. (2005). In Link and Tol (2004), we use FUND 2.7 to estimate total impacts and compare two scenarios: one without and one with a THC shutdown. These two scenarios are superimposed on a global warming scenario generated with the earth system model of intermediate complexity CLIMBER-2 (Rahmstorf and Ganopolski 1999) that is based on the IPCC IS92e scenario (Houghton et al. 1995). No sensitivity analysis was reported, indeed done. In Ceronsky et al. (2005), FUND 2.8 was used to estimate marginal impacts. The THC scenario applied is but one in a whole range of extreme climate scenarios. Both papers conclude that a THC shutdown is not dramatic; it may even be locally beneficial as warming slows down but does not turn into cooling, which would e.g. enhance agricultural production in large parts of Europe (Kuhlbrodt et al.2009). However, they have the distinct disadvantage that the spatial resolution is crude. Iceland, Ireland, and Norway, the countries most at risk of a THC shutdown, are grouped with Western Europe. When Iceland and Greece are averaged, any effects get lost in the aggregation. In the current paper, we use FUND 2.8 , but study each country separately. 


\section{The model}

The FUND model has been used for many purposes, but its main strength has always been the impacts of climate change. Earlier versions had 9 regions, and later versions 16. In this paper, we discard most of the model, and only retain the impact module. This part, however, is reparameterized for 207 countries. The impact module of FUND 2.8 is described extensively in Tol $(2002 \mathrm{a}, \mathrm{b}) .{ }^{1}$ However, the data presented in those studies were aggregated to a regional level. For some impacts, this was just a summation of country-based data. For other impacts, only regional information was available. We now present the national impacts module of FUND 2.8n. The source code, in Excel, can be found at www.fnu.zmaw.de/FUND.5679.0.html.

The climate change induced impact on cardiovascular mortality is based on Martens (1998). Impacts are assumed to vary linearly with the deviation of the actual temperature in the warmest or coldest month (for heat- and cold-related cases, respectively) in a given annual period from the temperature that the population is acclimatized to. This baseline temperature to which people are accustomed is based on the long-term temperature development in each geographic entity considered. It increases with warming too, using a geometric update procedure of the temperature, in which the gap between the temperature that people are used to and the actually observed temperature decreases by $10 \%$ per year. Thus, the impact is more than linear in the rate of warming. ${ }^{2}$ Heat- and cold-related cases are modeled separately, as are effects on people below and above 65 years of age. Heat-related cardiovascular disorders are assumed to be an urban phenomenon only. Respiratory mortality is treated in the same way as heat-related cardiovascular disorders, but is not limited to urban areas.

Schistosomiasis, dengue fever and malaria are assumed to be linearly related to warming. The vulnerability is based on the 1995 data in WHO (1995). These data have been used to calibrate FUND and to derive the income elasticities subsequently used in the assessments. Vulnerability is assumed to decline with per capita income growth, with an elasticity of 2.65. Diarrhea mortality is more than linear in warming with a power of 1.14, while vulnerability falls with an income elasticity of 1.58 . Diarrhea morbidity follows the same pattern, but with different parameters: 0.70 for the climate effect, and 0.42 for the income effect.

For all diseases except diarrhea, morbidity is assumed to be proportional to mortality, using the ratio given in WHO (1995). Mortality is valued at 200 times the annual per capita income of each deceased, morbidity at 0.8 times the annual per capita income of the diseased.

Cooling demand is based on Downing et al. (1996), who report regional results only. Impacts are assumed to be more than linear in warming, with a power of 1.5 , and to increase with economic growth with an elasticity of 0.8 . This income elasticity is

\footnotetext{
${ }^{1}$ Further information, including publications, technical descriptions, and source codes, can be found at www.fnu.zmaw.de/FUND.5679.0.html.

${ }^{2}$ In the regional version of $F U N D$, cardiovascular and respiratory impacts are quadratic in the level of temperature, but insensitive to the rate of warming. Intraregional variation does not allow for consistent parameterization with acclimatization.
} 
used to downscale regional sensitivities to a national level. Heating demand is based on the same source and follows the same procedure, but the sign is opposite and it is less than linear in warming with a power of only 0.5 . Water resources are also based on Downing et al. (1996). Impacts are assumed to change linearly with global warming; the assumed income elasticity is 0.85 .

Species loss varies quadratically with the rate of warming. The value of species loss is logistic in the rate of warming. The maximum amount that people are willing to pay to prevent climate change-induced species loss is set to be $\$ 50$ per person per year for people with the average income in the OECD in 1990. This maximum is proportional to income, and inversely proportional to the number of remaining species. So if people become richer, the willingness to pay increases and also if biodiversity decreases. This applies to all countries, not just those who lie below the OECD average. Poorer countries approach the maximum willingness to pay for biodiversity logistically as they grow richer.

The impacts of sea level rise are derived from Hoozemans et al. (1993) and Bijlsma et al. (1996). There are no more recent global impact studies; see Nicholls and Tol (2006) for a current review. Without coastal protection, wetland and dry land losses are assumed to be linearly related to sea level rise. The global mean sea level is determined by a geometric series depending on temperature that is calibrated based on the IS92a scenario in Kattenberg et al. (1996). Dry land losses decline linearly with protection, but wetland losses increase linearly with protection. The costs of dry land loss change linearly with per capita income and population density. The value of wetland losses follows the same logic as the value of species loss. Protection costs are assumed to be constant. The level of protection is set by a cost-benefit analysis, based on Fankhauser (1994), trading off the benefits of less dry land loss against the costs of protection and additional wetland loss. Dry land loss induces migration. Relocation is assumed to occur domestically. The cost of migration is assumed to equal 3.4 times the per capita income (Tol 1995).

The impacts of climate change on agriculture are based on the rate and level of climate change and on effects from $\mathrm{CO}_{2}$ fertilization. All are functions of temperature and are calibrated to Darwin et al. (1995), Fischer et al. (1996), Kane et al. (1992), and Tsigas et al. (1996). The impacts are split into three parts since there are various effects of climate and climate change influencing agricultural productivity. The first part is linearly related to the rate of warming and denotes the impact of the rate of climate change. These impacts are always negative. The second part is quadratic with respect to temperature, with an explicit climate optimum for agriculture for each country. Impacts are positive (negative) if a country moves towards (away from) its optimum. This denotes the impact of the level of climate change on agriculture, which assumes that for each country there is an optimal temperature for agriculture at which production is greatest. The third part is logarithmic in the atmospheric concentration of carbon dioxide, as $\mathrm{CO}_{2}$ fertilization is generally positive but there is a tendency for saturation. The national parameters equal the parameters of the region to which the country belongs in FUND 2.8. However, the climate scenario analyzed is resolved at country level. Impacts are expressed as fraction of national agricultural production. The share of agriculture in GDP is country-specific. It falls with an income elasticity of 0.31 .

Climate change impacts on forestry are calibrated to Perez-Garcia et al. (1997) and Sohngen et al. (2001). Impacts are assumed to vary linearly with warming and 
logarithmically with the atmospheric concentration of carbon dioxide, each with a weight of one half. Sensitivities decrease with economic growth with an income elasticity of 0.31 . This elasticity was used to downscale regional to national sensitivities.

\section{Scenarios}

The analysis of the impacts of a shutdown of the THC is based on the hosing experiment of Vellinga and Wood (2002), which was conducted using the HadCM3 model (Gordon et al. 2000), where the THC collapsed after one strong pulse of freshwater was added. After that, the simulation covered a century in which the THC could recover to some extent. In our assessment, we determine the difference in average temperature per country between the HadCM3 hosing scenario and the control run with stable THC conditions for the time period of the first three decades after the THC shutdown (Fig. 1). The magnitude of the temperature effect of a THC shutdown is then placed in context of a warming scenario.

We superimpose the obtained temperature difference on a FUND scenario of climate change, using a spatial pattern that is calibrated to the HadCM3 model. The FUND scenario of climate change (Tol 1999) follows the IPCC IS92a scenario (Leggett et al. 1992) for the economic and demographic development, and the emissions trajectory of the IS92f scenario. In such scenarios of rising greenhouse gas concentrations in the atmosphere, the THC gradually weakens (Wood et al. 1999; Vellinga and Wood 2008). In contrast, the THC shuts down rapidly and takes a long time to recover if scenarios are used that contain applications of large pulses of freshwater into the North Atlantic. In this assessment, it is therefore plausible to

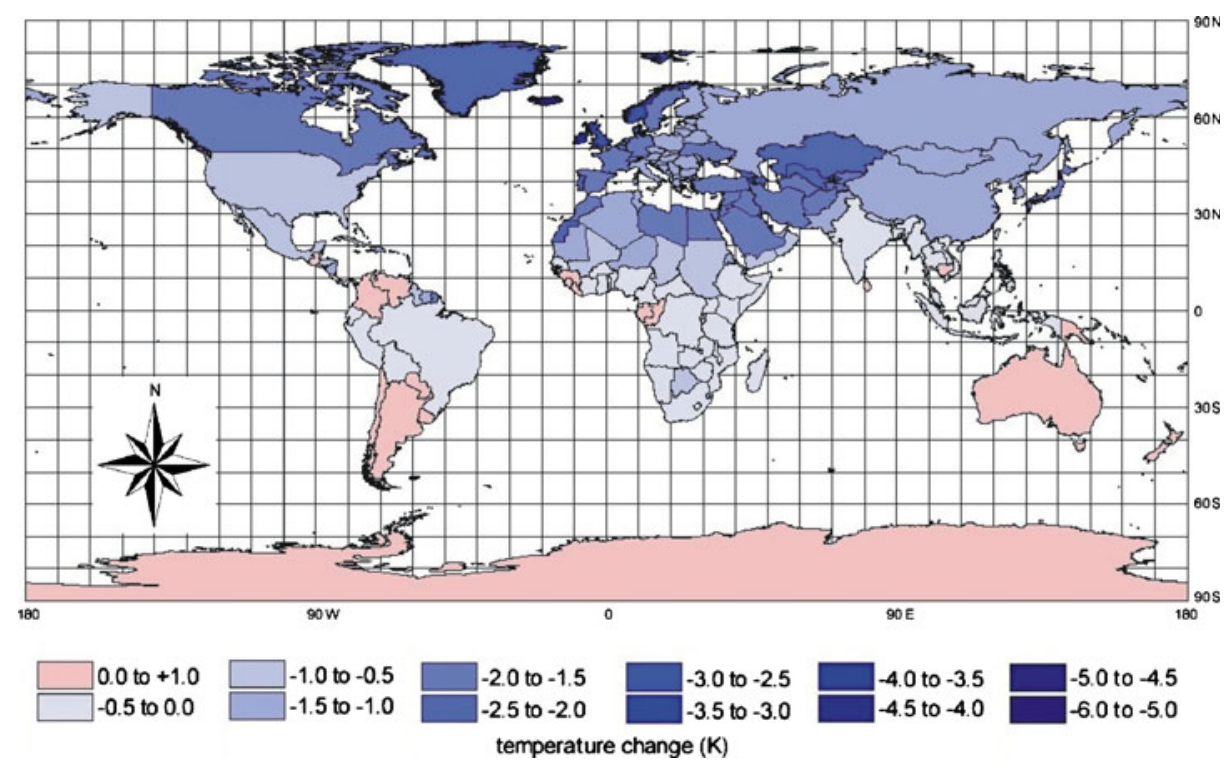

Fig. 1 The difference of the 2100-2129 average annual temperature between the HadCM3 THC shutdown scenario and the control scenario 
apply a gradual linear transition between the two states of the THC. It is assumed that the THC functions until 2070. After that, it slows down. In 2100, the full climate effect of the THC shutdown is assumed to take hold. Note that the dynamic effect of a THC shutdown on the sea level is disregarded in this assessment.

\section{Results}

Starting from present, the simulation extends through the twenty-first century. The market and non-market impacts of climate change are determined for the year 2100 and related to the initial conditions. Figure 2 shows the impact of the THC shutdown in 2100. The impact is measured as the difference between the monetized impact of climate change with and without a THC shutdown. Eight different situations can be distinguished.

In some places, a THC shutdown implies additional warming (1). If warming is already negative without a change in THC strength, additional warming is worse, and a THC shutdown has a negative impact $(1 \mathrm{~N})$. This is the case in Western Africa. Figure 3 shows the welfare impacts in Gambia as an example. If warming is generally positive, additional warming induced by a THC change is even better, and a THC shutdown has a positive impact (1P). This is the case for Australia and New Zealand (Fig. 3).
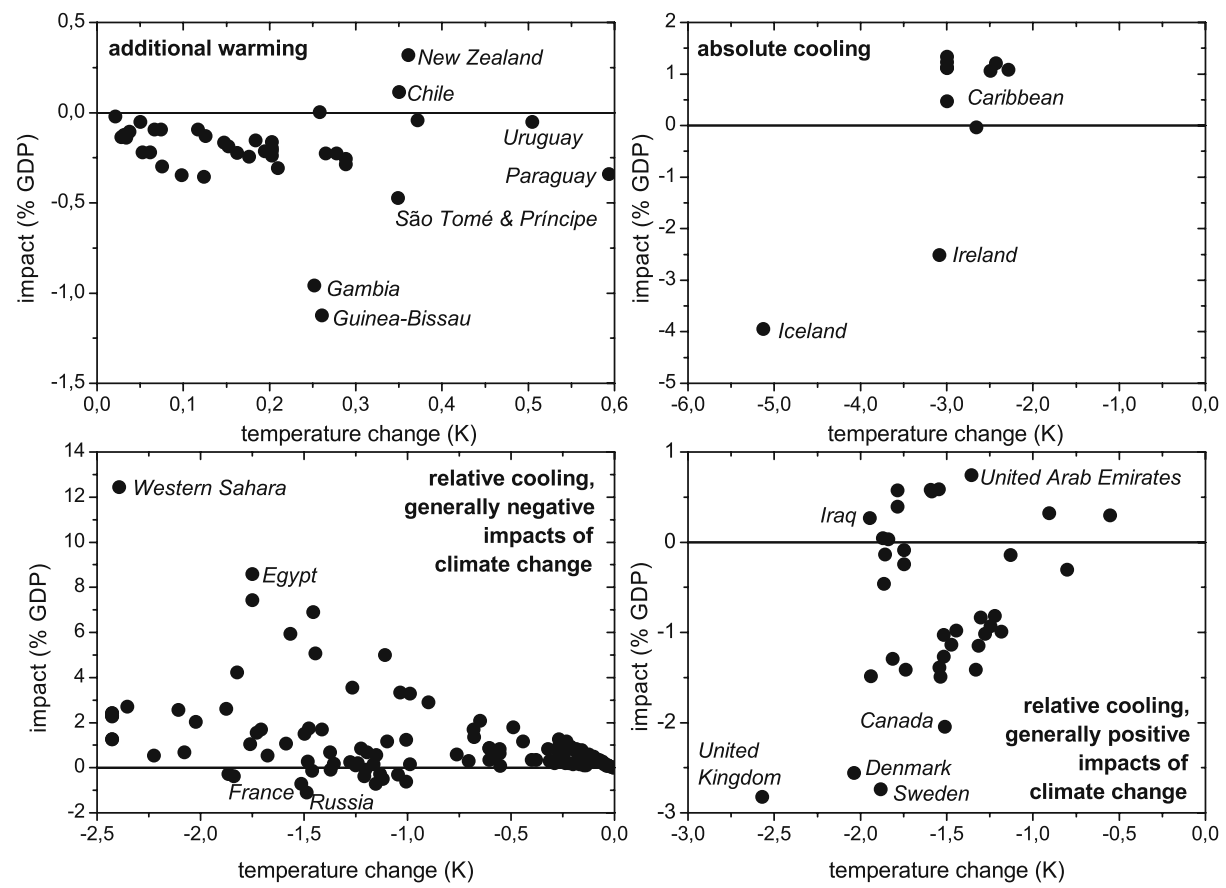

Fig. 2 The effect per country of a shutdown of the thermohaline circulation on the welfare impacts of climate change in 2100. In the top panels, countries warm faster (left panel) or cool (right panel). In the bottom panels, countries warm slower. The bottom left panel displays countries that benefit from a THC shutdown, the bottom right panel countries that are damaged by a THC shutdown 

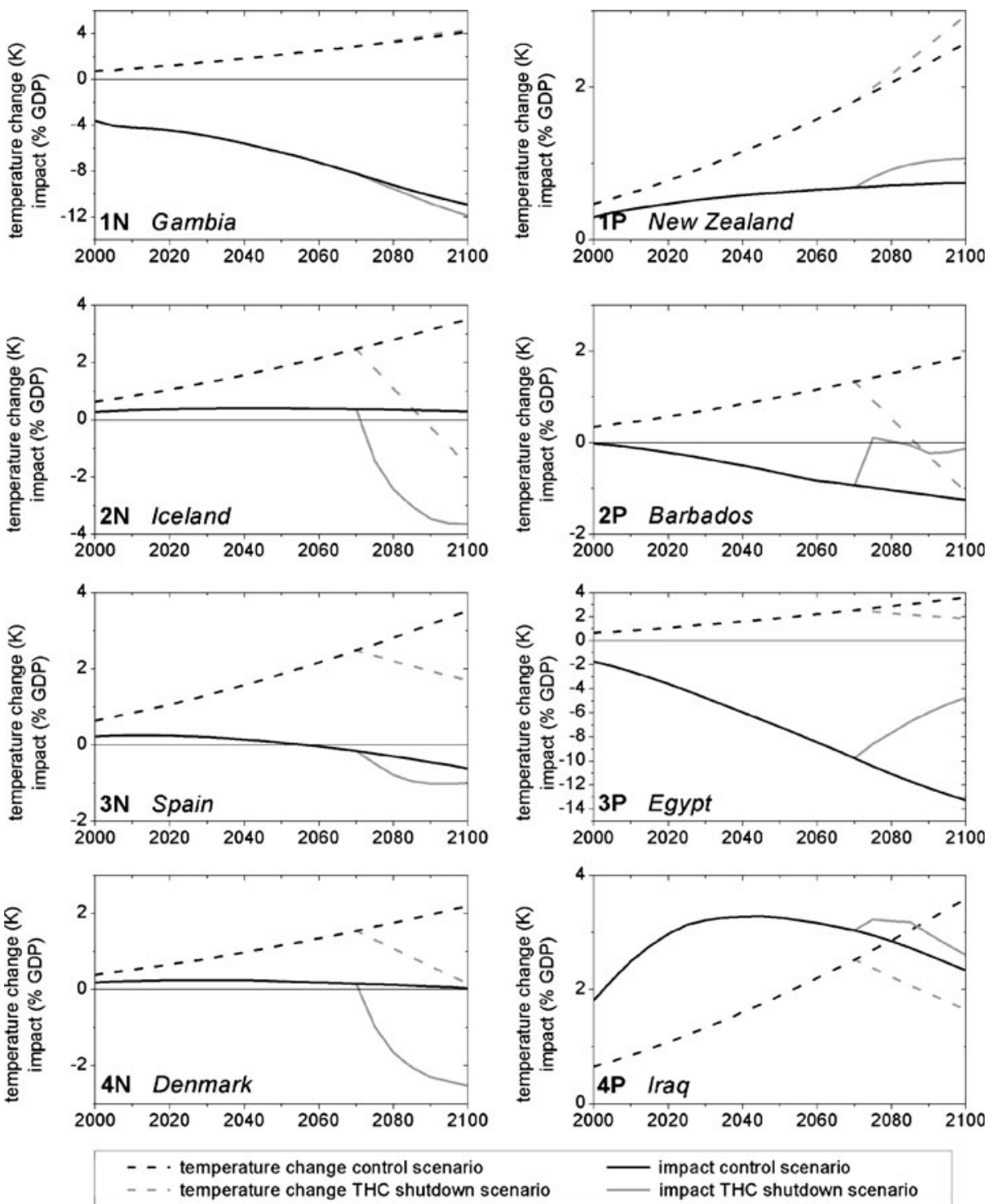

Fig. 3 The welfare impacts of climate change with and without a THC shutdown for eight selected countries. The solid lines denote welfare impacts, the dashed lines temperature change. The scale of the left $y$-axis applies to both quantities

In some places, a THC shutdown implies absolute cooling (2). In temperate or subarctic countries, further cooling has negative impacts $(2 \mathrm{~N})$. This is the case in Ireland and Iceland (Fig. 3). In subtropical or tropical countries, cooling has positive impacts that can be quite substantial in some countries (2P). This is the case in the Caribbean. Figure 3 shows results for Barbados as an example. 

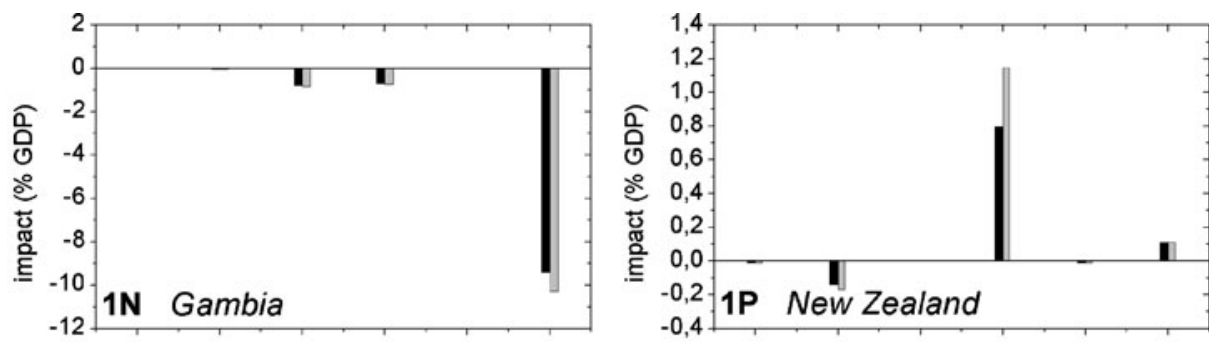

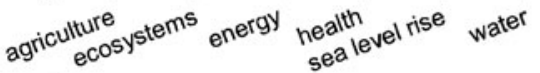
agriculture ecosystems energy nealth
sealevelrise water
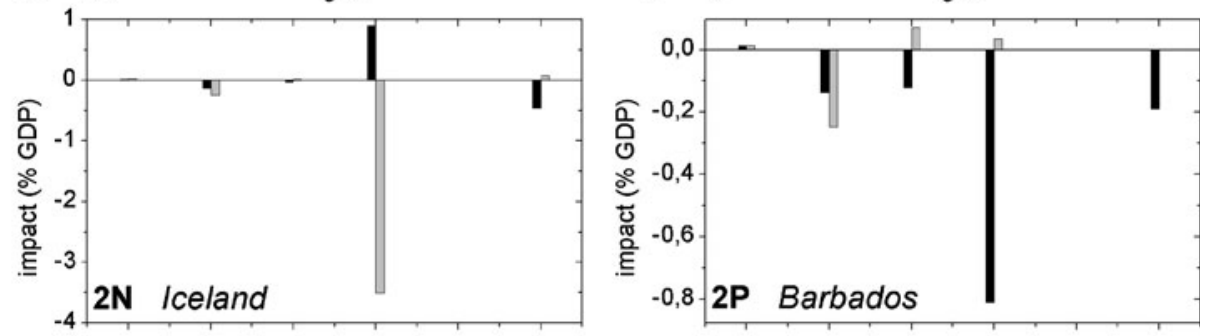

agriculture ecosystems energy health
sealevel rise water
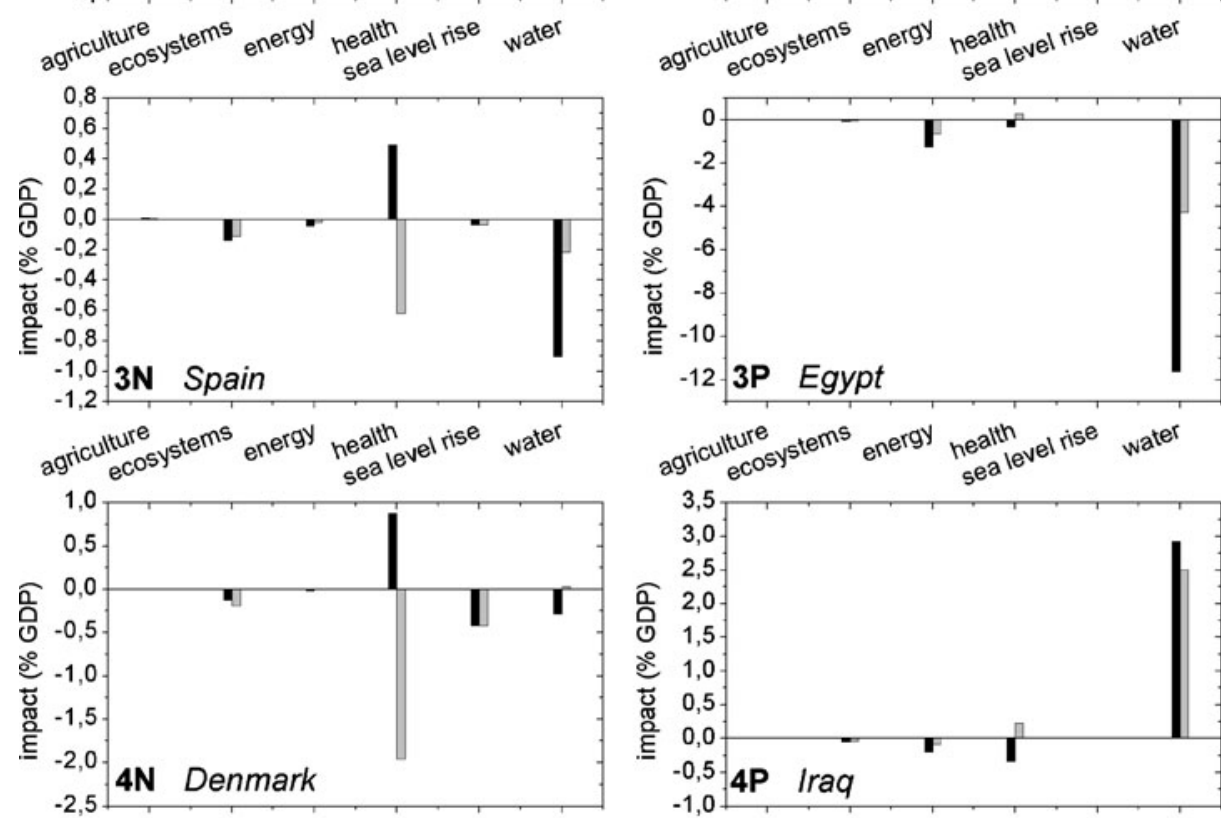

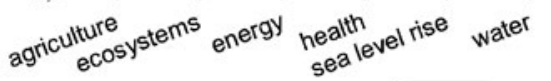

agriculture ecosystems energl nealth
sealevelrise water

Fig. 4 The welfare impacts per sector of climate change in 2100 with and without a THC for eight selected countries 
So far, the emerging pattern has been straightforward. However, in many countries the development is not as simple. It is often the case that a THC shutdown has an offsetting effect on a regional warming trend (3). If the impacts of climate change are negative to start with, one would expect a shift toward the better resulting from slower warming (3P). This is indeed the case in most countries. Figure 3 shows Egypt as an example. There are a few exceptions, however, e.g. France, Russia, and Spain (Fig. 2). The reason is that without a THC shutdown, the decreasing number of cold-related cardiovascular deaths resulting from warmer conditions contributes significantly to positive welfare impacts. With a THC shutdown, this effect disappears, and the overall impacts become more negative (3N).

If the impacts of climate change are positive without any change in THC strength, one would expect a worse overall impact as a consequence of slower warming (4). Again, this is the case in many countries. Figure 3 shows Denmark as an example $(4 \mathrm{~N})$. Here, the positive effect of global warming is not only weakened but reversed completely as the THC shutdown brings about considerable economic damages. However, there are exceptions to this development as well, e.g. in Iraq (Fig. 3). There, a weakening of the THC is actually initially beneficial, but the positive effect of a collapsed THC disappears over time as the difference in climaterelated economic impacts between the THC shutdown scenario and the control run diminishes (4P).

Figure 4 shows the impact per sector of a THC shutdown in 2100 for the eight selected countries. The most important impacts of a THC shutdown are on human health, energy consumption, and water resources, with economic impacts on ecosystems playing a smaller role. The impact on agriculture is negligible. Also, the impacts on sea level rise shown represent only part of the actual magnitude as this assessment disregards the dynamic sea level rise effects of the THC shutdown to start with.

Figure 5 depicts the impact of a change in THC strength aggregated to a global level by adding dollars without correcting for inequity aversion (Fankhauser et al. 1997, 1998). At this highly aggregate level, the differences seen in Figs. 3 and 4 are obviously hidden. The dominant pattern resembles that of Spain. Climate change first brings benefits, but the benefits start to decline after 2015, and turn into damages in 2060. A THC shutdown would bring about additional damages. The gap

Fig. 5 The global welfare impacts of climate change for scenarios with no impact on the thermohaline circulation, a slowdown, and a shutdown

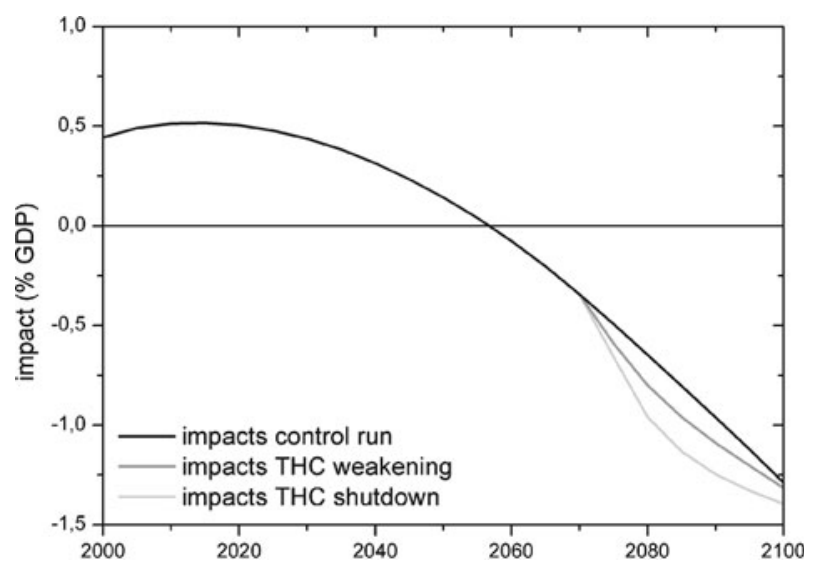


between the two scenarios widens rapidly, as the health benefits of warmer climates disappear. The gap then narrows again as the benefits of slowed warming become more important at the end of the simulation period.

\section{Sensitivity analysis}

In the analysis presented above, there are many assumptions about the parameters in FUND 2.8n, the scenarios that drive the model, and the shutdown of the THC. Some of these assumptions have little influence on the results. Other assumptions are very important. In this section, we report sensitivity analyses on the key parameters.

One of the crucial inputs is the assumed climate change due to the shutdown of the THC. Table 1 shows the 2100 welfare impacts for eight selected countries for the base scenario (no effect on the THC), the scenario used in Section 4 (THC shutdown), and a scenario halfway in between (THC slowdown). The eight selected countries are representative for the variety of responses observed. In a few countries, such as Spain, a slowdown of the THC has a positive effect, but a shutdown has a negative effect. In a larger number of countries, such as Denmark and Iceland, a weakening of the THC to half of its original strength leads to less than half the impact of a complete shutdown. Figure 5 shows that this pattern dominates at global scale. Furthermore, unreported experiments show that this impact pattern also holds for a weaker slowdown of the THC. In other countries, such as Egypt, Gambia, and New Zealand, the response is approximately linear. There are some countries, such as Iraq, in which the response is less than linear. In most of those countries, the impact of a slowdown is positive; and although the overall effect of a shutdown of the THC is still positive, the positive impacts begin to saturate while the negative impacts start to escalate. It is therefore no surprise that there are a few countries, such as Barbados, in which the difference between no change and a slowdown of the THC is positive, while the difference between slowdown and a shutdown is negative, even though the difference between no change and a THC shutdown is positive.

Table 2 shows a sensitivity analysis of the parameters that govern the estimated impacts on water resources, energy consumption, and cardiovascular and respiratory diseases. If either the sensitivity of water resources to climate change or the income elasticity is doubled, damages vary only slightly, and the impacts of a THC shutdown are just a little worse than in the reference scenario.

Table 1 The welfare impact of climate change in 2100 on selected countries for scenarios with no impact on the thermohaline circulation, a slowdown to $0.5 \mathrm{THC}_{\text {init }}$, and a complete shutdown

\begin{tabular}{lccc}
\hline & Impact (\% GDP) & Impact (\% GDP) & $\begin{array}{c}\text { Impact (\% GDP) } \\
\text { THC shutdown }\end{array}$ \\
\hline control scenario & THC weakening & -11.90 \\
1N Gambia & -10.94 & -11.42 & 1.07 \\
1P New Zealand & 0.75 & 0.91 & -3.65 \\
2N Iceland & 0.30 & -1.44 & -0.13 \\
2P Barbados & -1.25 & 0.22 & -0.99 \\
3N Spain & -0.62 & -0.55 & -4.69 \\
3P Egypt & -13.27 & -8.94 & -2.52 \\
4N Denmark & 0.04 & -1.04 & 2.61 \\
4P Iraq & 2.34 & 2.53 & \\
\hline
\end{tabular}


Table 2 The global welfare losses of climate change in 2100 with and without a THC shutdown for a range of parameter choices

\begin{tabular}{|c|c|c|c|c|c|}
\hline & $\begin{array}{l}\text { Impact } \\
\text { (\% GDP) } \\
\text { control } \\
\text { scenario }\end{array}$ & $\begin{array}{l}\text { Impact (\% GDP) } \\
\text { THC shutdown } \\
\text { scenario }\end{array}$ & $\begin{array}{l}\text { Difference } \\
\text { (\% GDP) }\end{array}$ & $\begin{array}{l}\text { Change from } \\
\text { Base control } \\
\text { scenario }(\%)\end{array}$ & $\begin{array}{l}\text { Change from } \\
\text { Base THC } \\
\text { shutdown } \\
\text { scenario (\%) }\end{array}$ \\
\hline Base & 1.29 & 1.39 & 0.10 & & \\
\hline $\begin{array}{l}\text { Water: } \\
\text { Sensitivity }\end{array}$ & 1.31 & 1.42 & 0.11 & +1.7 & +1.7 \\
\hline $\begin{array}{l}\text { Water: Income } \\
\text { elasticity }\end{array}$ & 1.23 & 1.35 & 0.12 & -4.5 & -3.3 \\
\hline $\begin{array}{l}\text { Heating: } \\
\text { Sensitivity }\end{array}$ & 0.49 & 0.73 & 0.24 & -61.7 & -47.7 \\
\hline $\begin{array}{l}\text { Heating: } \\
\text { Non-linearity }\end{array}$ & 0.56 & 0.96 & 0.40 & -56.3 & -31.0 \\
\hline $\begin{array}{l}\text { Heating: } \\
\text { Income } \\
\text { elasticity }\end{array}$ & 1.59 & 1.65 & 0.06 & +23.5 & +18.2 \\
\hline $\begin{array}{l}\text { Cooling: } \\
\text { Sensitivity }\end{array}$ & 3.48 & 2.93 & -0.55 & +170.3 & +110.1 \\
\hline $\begin{array}{l}\text { Cooling: } \\
\text { Non-linearity }\end{array}$ & 0.23 & 0.73 & 0.50 & -82.2 & -47.7 \\
\hline $\begin{array}{l}\text { Cooling: } \\
\text { Income } \\
\text { elasticity }\end{array}$ & 0.44 & 0.80 & 0.36 & -65.7 & -42.7 \\
\hline Respiratory & 1.40 & 1.39 & -0.01 & +9.0 & -0.1 \\
\hline $\begin{array}{l}\text { Cardiovascular, } \\
\text { heat }\end{array}$ & 1.66 & 1.51 & -0.15 & +29.1 & +8.2 \\
\hline $\begin{array}{l}\text { Cardiovascular, } \\
\text { cold }\end{array}$ & 0.54 & 1.36 & 0.82 & -58.4 & -2.3 \\
\hline Urbanization & 1.33 & 1.41 & 0.08 & +3.6 & +1.1 \\
\hline Aging & 1.21 & 1.43 & 0.22 & -6.4 & +2.7 \\
\hline $\begin{array}{l}\text { Value of a } \\
\text { statistical life }\end{array}$ & 0.72 & 1.60 & 0.88 & -43.9 & +14.9 \\
\hline $\begin{array}{l}\text { Value of a } \\
\text { year disabled }\end{array}$ & 1.33 & 1.43 & 0.10 & +3.7 & +2.5 \\
\hline
\end{tabular}

A doubling of the sensitivity of heating energy to changes in temperature causes damages to decrease because savings on heating are beneficial; however, the temperature change due to a THC shutdown becomes more important as the world cools. If heating were linearly related to temperature, rather than the square root as in the base scenario, the result would be qualitatively the same. The opposite effects are observed when the income elasticity is doubled so that future energy use for heating is smaller. Doubling the sensitivity of cooling energy leads to increased damages both due to climate change and due to a THC shutdown. If cooling changed linearly with temperature rather than being proportional to the 1.5 th power of temperature as in the base case, damages would fall in both scenarios. However, the effect is less pronounced in the scenario with the THC shutdown, so that the difference between the scenarios increases over time. The same pattern is observed for a doubling of the income elasticity, which causes energy use for cooling to decrease over time. 
A twofold increase of the sensitivity of heat-related cardiovascular or respiratory mortality causes climate change impacts to increase (Table 2). A THC shutdown would have positive effects, as warming is less pronounced. If the sensitivity of coldrelated cardiovascular mortality is doubled, the opposite pattern can be observed. A doubling of the rate of urbanization leads to higher climate change impacts as the number of heat-related deaths rises; by the same token, the effect of a THC shutdown is reduced. A doubling of the rate of aging has the opposite effect, by particularly increasing cold-related cardiovascular mortality. Doubling the value of a statistical life reduces the impact of climate change because of the higher weight placed on the avoided cold-related deaths in the rich and temperate countries. These benefits disappear with a THC shutdown.

\section{Discussion and conclusion}

In this paper, we present estimates of the welfare losses incurred from a rapid shutdown of the THC. This assessment considers only the temperature effect of such development. However, there are also considerable impacts of a weaker THC on other components of the earth's ocean-atmosphere system, such as altered precipitation patterns and a significantly augmented background sea level rise. These developments also have profound socio-economic consequences but are not yet incorporated in this model. Consequently, the results presented in this paper can by no means be considered as concrete predictions of welfare impacts of a THC shutdown on a country level. Instead, they should rather be viewed as an indicator of the regional heterogeneity of such impacts, in which the emerging patterns and trends are of greater importance than the actual absolute values. It might very well be possible that the inclusion of impacts from precipitation and sea level rise effects would point to trends in welfare impacts that are qualitatively different from the results shown here.

In some places, a THC shutdown reduces the rate of warming, and this may well be a benefit. Such is the case in Northern Africa, in which the particularly negative socioeconomic impacts of global warming are offset to a large degree in case of a THC shutdown. This effect dominates the result presented in Link and Tol (2004). However, Link and Tol (2004) ignored the additional warming in some parts of the world that is here shown to have mostly negative impacts. Furthermore, the crude spatial resolution of the assessment in Link and Tol (2004) did not allow the investigation of places where a THC shutdown would not lead to slowed warming but to an absolute cooling that also increases damages. Finally, at the finer spatial scale used here, health impacts are modeled in a more realistic way-particularly, a shutdown of the THC causes a considerable change in cold-related cardiovascular mortality.

Overall, we find that a complete THC shutdown has a negative effect on welfare; the same is true, but to a lesser extent, for a partial THC slowdown. The best guess estimate is $-0.1 \%$ of global GDP for a THC shutdown by the end of the simulation period. However, this additional effect is quite small in comparison to the total socioeconomic impact of globally changing climate conditions. In the late 21 st century, the loss in global GDP incurred by a THC shutdown is approximately twice as large as 
the effect on GDP by THC weakening, even though this still amounts to less than $0.5 \%$ of global GDP (Fig. 5). Sensitivity analyses of the key parameters of FUND show estimates in the range of $-0.9 \%$ GDP to $+0.6 \%$ GDP. On the national scale impacts are, of course, in some regions somewhat larger. However, only in very few countries does the influence of a THC shutdown reach levels that exceed two per cent of GDP. As expected, this is the case in the Scandinavian countries, Great Britain and Ireland, and in Canada, the countries most directly affected by the changing circulation pattern in the vicinity.

Yet, it has to be noted that a scenario that leads to a THC shutdown within the twenty-first century such as the one used in this paper is rather unlikely to actually come true. In the 4th IPCC Assessment Report, the probability of such an event is estimated to be only 5-10\% (Meehl et al. 2007). Also, the simulation results indicate that the magnitude of welfare impacts induced by temperature changes following a THC shutdown is quite limited compared to the consequences of greenhouse gas induced warming itself, which suggests that the latter is a much greater danger to human welfare. This evaluation, however, is likely to be considerably affected if precipitation and sea level changes following a THC shutdown are considered in the model as well, which is beyond the scope of the assessment presented here.

Our results are obviously specific to the model and scenario chosen, even though a model intercomparison of the response of the THC to climate change shows that the HadCM3 model, on which our THC shutdown scenario is based, is well in line with other GCMs (Stouffer et al. 2006). However, since the THC shutdown scenario is moderate over land, other impact models applying this scenario would have to be very nonlinear to lead to drastically different results than FUND 2.8n.

The assessment with this model version only looks at the overall economic impacts but does explicitly include economic sectors that are of particular importance for the North Atlantic region. E.g., fisheries are omitted. While fisheries are only a small part of the world economy-and therefore do not bias the global results much-they are particularly important for the economy of those countries that are considerably affected by a shutdown of the THC. Therefore, their national results are likely to be biased. Assessments of the development of the Barents Sea cod fishery in scenarios of global warming with and without a shutdown of the THC show that fisheries benefit from increased reproductive success and stock growth due to temperature increases of the cod spawning grounds (Link and Tol 2006, 2009). This positive effect is offset if the THC breaks down causing the cod fishery to become unprofitable in the long run. Nonetheless, the overall economic consequences remain rather limited. Similarly, tourism is omitted. Here, impacts mostly consist of redistribution, so the global impact would not be affected much; however, with global warming, the cool countries in the North Atlantic region would become more popular destinations of summer tourism (Hamilton et al. 2005). This advantage vanishes with a THC shutdown.

The simplifications made by FUND $2.8 n$ introduce a bias of unknown sign and size. Our results should therefore be interpreted with the necessary caution. Future research should address these caveats. Nonetheless, while the total global effect of temperature changes of a THC shutdown appears to be limited, some national results are quite substantial. Note that the THC shutdown is the only aspect of climate change, so far, for which the impacts are larger in rich and temperate countries. The policy implications arising from this fact are also subject of future research. 
Acknowledgements The data of the THC hosing experiment and the control run have been supplied by the Climate Impacts LINK Project (DEFRA Contract EPG 1/1/154) on behalf of the Hadley Centre and U.K. Meteorological Office. Financial support by the Hamburg University Innovation Fund and the Princeton Environmental Institute is gratefully acknowledged.

Open Access This article is distributed under the terms of the Creative Commons Attribution Noncommercial License which permits any noncommercial use, distribution, and reproduction in any medium, provided the original author(s) and source are credited.

\section{References}

Bijlsma L et al (1996) Coastal zones and small islands. In: Watson RT et al (eds) Climate change 1995: impacts, adaptation and mitigation of climate change: scientific technical analyses. Contribution of working group II to the second assessment report of the Intergovernmental Panel on Climate Change, Cambridge University Press, Cambridge, pp 289-324

Bosello F, Roson R, Tol RSJ (2007) Economy-wide estimates of the implications of climate change: sea level rise. Environ Resour Econ 37:549-571

Ceronsky M, Anthoff D, Hepburn CJ, Tol RSJ (2005) Checking the price tag on catastrophe: the social cost of carbon under non-linear climate response. Working paper FNU-87, Research Unit Sustainability and Global Change, Hamburg University

Darwin RF et al (1995) World agriculture and climate change-economic adaptations. US Department of Agriculture, Washington

Downing TE et al (1996) Full fuel cycle study: evaluation of the global warming externality for fossil fuel cycles with and without $\mathrm{CO}_{2}$ abatement and for two reference scenarios. Environmental Change Unit, Oxford University, Oxford

Fankhauser S (1994) Protection vs retreat-the economic cost of sea level rise. Environ Plann A 27:299-319

Fankhauser S, Tol RSJ (2005) On climate change and economic growth. Resour Energy Econ 27:1-17

Fankhauser S, Tol RSJ, Pearce DW (1997) The aggregation of climate change damages: a welfare theoretic approach. Environ Resour Econ 10:249-266

Fankhauser S, Tol RSJ, Pearce DW (1998) Extensions and alternatives to climate change impact valuation: on the critique of IPCC working group III's impact estimates. Environ Dev Econ 3:59-81

Fischer $\mathrm{G}$ et al (1996) Impacts of potential climate change on global and regional food production and vulnerability. In: Downing TE (ed) Climate change and world food security. Springer, Berlin, pp 115-159

Fischer G, Shah M, Tubiello FN, van Velhuizen H (2005) Socio-economic and climate change impacts on agriculture: an integrated assessment, 1990-2080. Philos Trans R Soc B 360:2067-2083

Gordon C et al (2000) The simulation of SST, sea-ice extents and ocean heat transport in a version of the Hadley Centre coupled model without flux adjustments. Clim Dyn 16:147-168

Gregory JM et al (2005) A model intercomparison of changes in the Atlantic thermohaline circulation in response to increasing atmospheric $\mathrm{CO}_{2}$ concentration. Geophys Res Lett 32:L12703

Hamilton JM, Maddison DJ, Tol RSJ (2005) The effects of climate change on international tourism. Clim Res 29:255-268

Higgins PAT, Vellinga M (2004) Ecosystem responses to abrupt climate change: teleconnections, scale and the hydrological cycle. Clim Change 64:127-142

Hoozemans FMJ, Marchand M, Pennekamp HA (1993) A global vulnerability analysis: vulnerability assessment for population, coastal wetlands and rice production on a global scale, $2 \mathrm{nd}$ edn. Delft Hydraulics, The Netherlands

Houghton JT et al (1995) Climate change 1995. Cambridge University Press, Cambridge

Kane S, Reilly JM, Tobey J (1992) An empirical study of the economic effects of climate change on world agriculture. Clim Change 21:17-35

Kattenberg A et al (1996) Climate models-projections of future climate. In: Houghton JT et al (ed) Climate change 1995: the science of climate change. Cambridge University Press, Cambridge, pp 285-357

Keller K, Bolker BM, Bradford DF (2004) Uncertain climate thresholds and optimal economic growth. J Environ Econ Manage 48:723-741 
Köhler P, Joos F, Gerber S, Knutti R (2005) Simulated changes in vegetation distribution, land carbon storage, and atmospheric $\mathrm{CO}_{2}$ in response to a collapse of the North Atlantic thermohaline circulation. Clim Dyn 25:689-708

Kuhlbrodt T et al (2009) An integrated assessment of changes in the thermohaline circulation. Clim Change 96:489-537

Leggett J, Pepper WJ, Swart RJ (1992) Emissions scenarios for the IPCC: an update. In: Houghton JT, Callander BA, Varney SK (eds) Climate change 1992. The supplementary report to the IPCC Scientific Assessment, vol 1, 1st edn, Cambridge University Press, Cambridge, pp 71-95

Lenton TM et al (2008) Tipping elements in the Earth's climate system. Proc Natl Acad Sci U S A 105:1786-1793

Levermann A, Griesel A, Hofmann M, Montoya M, Rahmstorf S (2005) Dynamic sea level changes following changes in the thermohaline circulation. Clim Dyn 24:347-354

Link PM, Tol RSJ (2004) Possible economic impacts of a shutdown of the thermohaline circulation: an application of FUND. Port Econ J 3:99-114

Link PM, Tol RSJ (2006) Economic impacts on key Barents Sea fisheries arising from changes in the strength of the Atlantic thermohaline circulation. ICES J Mar Sci 63(4):611-625

Link PM, Tol RSJ (2009) Economic impacts on key Barents Sea fisheries arising from changes in the strength of the Atlantic thermohaline circulation. Glob Environ Change 19:422-433

Manabe S, Stouffer RJ (1994) Multiple-century response of a coupled ocean-atmosphere model for an increase of atmospheric carbon dioxide. J Climate 7:5-23

Martens WJM (1998) Climate change, thermal stress and mortality changes. Soc Sci Med 46(3): 331-344

Meehl GA et al (2007) Global climate projections. In: Solomon S et al (eds) Climate change 2007: the physical science basis. Contribution of working group I to the fourth assessment report of the intergovernmental panel on climate change, Cambridge University Press, Cambridge

Mikolajewicz U, Gröger M, Maier-Reimer E, Schurgers G, Vizcaíno M, Winguth AME (2007) Longterm effects of anthropogeneic $\mathrm{CO}_{2}$ emissions simulated with a complex earth system model. Clim Dyn 28:599-633

Nævdal E, Oppenheimer M (2007) The economics of the thermohaline circulation-a problem with multiple thresholds of unknown locations. Resour Energy Econ 29:262-283

Nicholls RJ, Tol RSJ (2006) Impacts and responses to sea-level rise: a global analysis of the SRES scenarios over the twenty-first century. Philos Trans R Soc A 364:1073-1095

Nicholls RJ, Tol RSJ, Vafeidis AT (2008) Global estimates of the impact of a collapse of the West Antarctic ice sheet: an application of FUND. Clim Change 91:171-191

Perez-Garcia JM et al (1997) Economic impacts of climatic change on the global forest sector: an integrated ecological/economic assessment. Crit Rev Environ Sci Technol 27:S123-S138

Rahmstorf S, Ganopolski A (1999) Long-term global warming scenarios computed with an efficient coupled climate model. Clim Change 43:353-367

Sohngen B, Mendelsohn R, Sedjo R (2001) A global model of climate change impacts on timber markets. J Agric Resour Econ 26(2):326-343

Stocker TF, Schmittner A (1997) Influence of $\mathrm{CO}_{2}$ emission rates on the stability of the thermohaline circulation. Nature 388:862-865

Stouffer RJ et al (2006) Investigating the causes of the response of the thermohaline circulation to past and future climate changes. J Climate 19:1365-1387

Tol RSJ (1995) The damage costs of climate change-towards more comprehensive calculations. Environ Resour Econ 5:353-374

Tol RSJ (1999) Spatial and temporal efficiency in climate change: applications of FUND. Environ Resour Econ 14:33-49

Tol RSJ (2002a) Estimates of the damage costs of climate change. Part I: benchmark estimates. Environ Resour Econ 21:47-73

Tol RSJ (2002b) Estimates of the damage costs of climate change. Part II: dynamic estimates. Environ Resour Econ 21:135-160

Tol RSJ (2009) The economic effects of climate change. J Econ Perspect 23:29-51

Tsigas ME, Frisvold GB, Kuhn B (1996) Global climate change in agriculture. In: Hertel TW (ed) Global trade analysis: modelling and applications. Cambridge University Press, Cambridge

Vellinga M (2004) Robustness of climate response in HadCM3 to various perturbations of the Atlantic meridional overturning circulation. Hadley Centre technical notes, Exeter

Vellinga M, Wood RA (2002) Global climatic impacts of a collapse of the Atlantic thermohaline circulation. Clim Change 54:251-267 
Vellinga M, Wood RA (2008) Impacts of thermohaline circulation shutdown in the twenty-first century. Clim Change 91:43-63

Wood RA, Keen AB, Mitchell JFB, Gregory JM (1999) Changing spatial structure of the thermohaline circulation in response to atmospheric $\mathrm{CO}_{2}$ forcing in a climate model. Nature 399:572-575

Wood RA, Vellinga M, Thorpe RB (2003) Global warming and thermohaline circulation stability. Philos Trans R Soc A 361:1961-1975

Wood RA et al (2006) Towards a risk assessment for shutdown of the atlantic thermohaline circulation. In: Schellnhuber et al (eds) Avoiding dangerous climate change. Cambridge University Press, Cambridge

World Health Organization (WHO) (1995) Global burden of disease database. http://www.who.int/ topics/global_burden_of_disease/en/.Cited 8 May 2008

Zickfeld $\mathrm{K}$ et al (2007) Expert judgments on the response of the Atlantic meridional overturning circulation to climate change. Clim Change 82:235-265 